Clinical laboratory staff are exposed to a considerable hazard by having to process specimens of blood, urine, and secretions that may contain high titres of virus. Infection may occur via contamination of cuts or abrasions. Since two contacts may have been contaminated in this way it is fortunate that our patient was probably not excreting virus in the urine until after her transfer to Coppetts Wood Hospital. ${ }^{1}$ Nevertheless, it is encouraging that despite the high level of viraemia there was no evidence of clinical or subclinical infection among those who handled blood specimens.

There will always be the possibility that patients with undiagnosed Lassa fever may be admitted to district general hospitals, particularly if, as in this case, a history of residence within a rural area is not readily forthcoming. Prevention of spread within such hospitals will depend on general policies for the control of infection within the wards and safe handling of specimens within laboratories. Hospitals must have appropriate isolation facilities for managing patients with infectious diseases.

So far as we are aware, not a single case of transmission of Lassa fever from person to person has occurred outside the African continent. Hospital practice in parts of tropical Africa may be particularly hazardous because of certain factors that do not apply in other countries: patients with uncontrolled haemorrhage must often be nursed on open wards where cleanliness is inadequate and decontamination impossible, and cross- infection may occur through the necessary economy of using repeatedly unsterilised equipment such as needles.

Perhaps in view of our experiences and the comments made above some recommendations in the DHSS memorandum on Lassa fever ${ }^{5}$ should be revised.

We are grateful to Dr Brian Creamer for permission to publish details of his patient ; to many other members of staff at St Thomas's Hospital who were closely involved and associated with surveillance; and to Mrs Helen Peston (information and liaison officer) and the hospital telephonists who coped admirably with a deluge of calls.

\section{References}

${ }^{1}$ Emond RTD, Bannister B, Lloyd G, Southee TJ, Bowen ETW. A case of Lassa fever: clinical and virological findings. $\mathrm{Br} M e d f$ 1982;285:1001-2.

${ }^{2}$ Grundy DJ, Bowen ETW, Lloyd G. Isolated case of Lassa fever in Zaria, Northern Nigeria. Lancet 1980 ;ii:649-50.

${ }^{3}$ Galbraith NS, Berrie JRH, Forbes P, Young S. Public health aspects of viral haemorrhagic fevers in Britain. Roy Soc Health 7 1978;98:152-61.

4 Carey DE, Kemp GE, White HA. Lassa fever: epidemiological aspects of the 1970 epidemic. Jos, Nigeria. Trans $R$ Soc Trop Med Hyg 1972;66: 402-8.

${ }^{5}$ Department of Health and Social Security, Welsh Office. Memorandum on Lassa fever. London: HMSO, 1976.

(Accepted 2 August 1982)

\title{
European distribution of Paget's disease of bone
}

\author{
F M DETHERIDGE， P B GUYER， D J P BARKER
}

\begin{abstract}
The prevalence of Paget's disease of bone was mapped from 1416 replies to a postal questionnaire sent to radiologists throughout Western Europe. Subsequently radiological surveys were carried out in 13 towns in nine countries. The two surveys showed a remarkable geographical distribution. The prevalence of the disease was higher in Britain than in any other Western European country. Only in France did the prevalences reach the lowest values among those previously recorded in a survey of 31 British towns. The lowest rates in any country were in Sweden and Norway.
\end{abstract}

These findings have implications for the hypothesis that the disease is caused by a virus infection and suggest the existence of one or more as yet unknown cofactors.

\section{Introduction}

Clinical data suggest that Paget's disease of bone has a remarkable geographical localisation, with the highest prevalences being in Britain, Western Europe, North America, Australia, and

\footnotetext{
MRC Environmental Epidemiology Unit, Southampton General Hospital, Southampton SO9 4XY

F M DETHERIDGE, BSC, MSC, research fellow

D J P BARKER, PHD, FRCP, professor of clinical epidemiology

Department of Radiology, Southampton General Hospital, Southampton SO9 4XY

P B GUYER, DM, FRCR, consultant radiologist
}

New Zealand. ${ }^{1}$ Radiological surveys among hospital patients aged 55 and over in Britain, North America, and Australia have confirmed these high prevalences. ${ }^{2}$ In Britain the overall ageand sex-standardised prevalence in some 29000 radiographs from 31 towns was $5.0 \%(6.2 \%$ among men, $3.9 \%$ among women). ${ }^{3}$ Clinical, radiological, and necropsy data from other European countries suggest that there are pronounced variations in prevalence, but there has been no systematic study to verify this. ${ }^{2}$

We report here the results of a survey of the prevalence of Paget's disease in Western Europe based on radiologists' replies to a postal questionnaire and radiological surveys carried out in nine countries.

\section{Methods \\ POSTAL QUESTIONNAIRE SURVEY}

A postal questionnaire was sent to a notional $50 \%$ sample of radiologists in Western Europe. The sample was drawn from a listing supplied by an international mailing company which tries to maintain an up-to-date register of radiologists. The questionnaire inquired about the average frequency with which Paget's disease was seen, as either the principal abnormality or, more often, as an incidental one, and asked respondents whether they were general radiologists or specialists-for example, neuroradiologists.

In a pilot survey the questionnaire was sent to all radiologists in (a) four British towns, (b) Northern Ireland, where the prevalence was thought to be similar to that in Britain, (c) Norway, where there is evidence of a low prevalence, ${ }^{4}$ and $(d)$ Luxembourg, which is approximately in the centre of the area to be surveyed. The replies and comments received led to our modifying the question on frequency so that the number of possible responses was increased from four (once a week or more, once a month, once a year, less than once a year) to seven (once a week or more, once every two weeks, once a month, 
once every two months, once every six months, once a year, less than once a year).

The modified questionnaire was sent to all listed radiologists in Italy, Austria, Belgium, and Eire, and to all listed radiologists in a sample of towns throughout France, West Germany, Holland, Denmark, Switzerland, Spain, and Portugal. A total of 4755 questionnaires was sent out. In addition 284 questionnaires were sent to the radiologists in 62 British towns, in 31 of which the radiological prevalence was known. ${ }^{3}$ No listing of radiologists in Greece could be obtained, and no questionnaires were sent to Sweden or Finland because there was already clear evidence of very low prevalences. ${ }^{2}$

\section{RADIOLOGICAL SURVEY}

Radiological surveys were carried out in 13 towns. The towns were selected to encompass the range of frequencies of Paget's disease as elicited by the postal questionnaire, the geographical extent of the survey, and areas of various types such as urban, rural, or heavily industrial.

The method used was similar to that used previously. ${ }^{3}$ In each town a consecutive sample of abdominal radiographs of people aged 55 and over was taken from films stored in hospitals. The selected films showed the entire pelvis and sacrum, the femoral heads, and all lumbar vertebrae-sites that are affected in $95 \%$ of patients with Paget's disease. Whenever possible samples of about 1000 radiographs were drawn for each town, with similar numbers for men and women. The films were initially classified by a trained observer (FMD) into three groups: positive (unequivocal signs of Paget's disease), doubtful, and negative. A second observer (PBG, a radiologist) then examined all the positive and doubtful films and a one-in-10 sample of the negative ones. Standardised criteria were used for diagnosing Paget's disease. The two previous surveys in Britain have shown that the radiologist's observations have high levels of repeatability. After completion of the present survey a sample of 42 radiographs from four towns in four different countries was re-examined to determine whether this level of repeatability had been maintained.

A recent study of the trace element content of Pagetoid bone provided the opportunity to test the validity of the radiologist's diagnostic criteria. ${ }^{5}$ Bone biopsy specimens were taken at necropsy from the iliac blades of 21 subjects in whom postmortem pelvic radiographs had shown the disease in some part of the iliac blade. In 19 out of 21 subjects the biopsy showed histological signs of the disease (the patchy distribution of the pathological changes in Paget's disease is one possible explanation for the lack of concordance between the radiological and histological appearances in the other two cases).

The method differed in two ways from that used in Britain. Firstly, there were large private hospitals in some of the European towns. To achieve better comparability between the populations surveyed in each town radiographs in private hospitals were not used. Secondly, radiographs taken specifically to show the skeleton were not used in the European survey. The British surveys have shown that the prevalence of Paget's disease is higher in skeletal radiographs than in

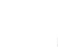
saw the disease. other radiographs showing the pelvis - for example, those taken during intravenous pyelography, barium studies, and plain abdominal examinations. In the combined results for the 31 British towns the age-standardised prevalence was $6.3 \%$ in skeletal radiographs (which comprised about $20 \%$ of all the radiographs) compared with a prevalence of $4.6 \%$ in other radiographs. The prevalence recorded in a town will therefore be influenced by the proportion of radiographs which are skeletal. This will depend on the kind of specialist units whose radiographs are being sampled (many European hospitals not having centralised radiograph archives) and on referral practices and indications for radiography among patients with skeletal symptoms. Omission of skeletal radiographs from the survey eliminates this potential source of bias.

\section{Results}

\section{POSTAL QUESTIONNAIRE}

The $\mathbf{4 7 5 5}$ questionnaires sent to countries other than Britain yielded 1301 replies, a response rate of $27 \%$. A factor contributing to this low response rate was that the listing of radiologists was not wholly accurate. In Britain replies were received from 198 out of 284 radiologists, a response rate of $70 \%$.

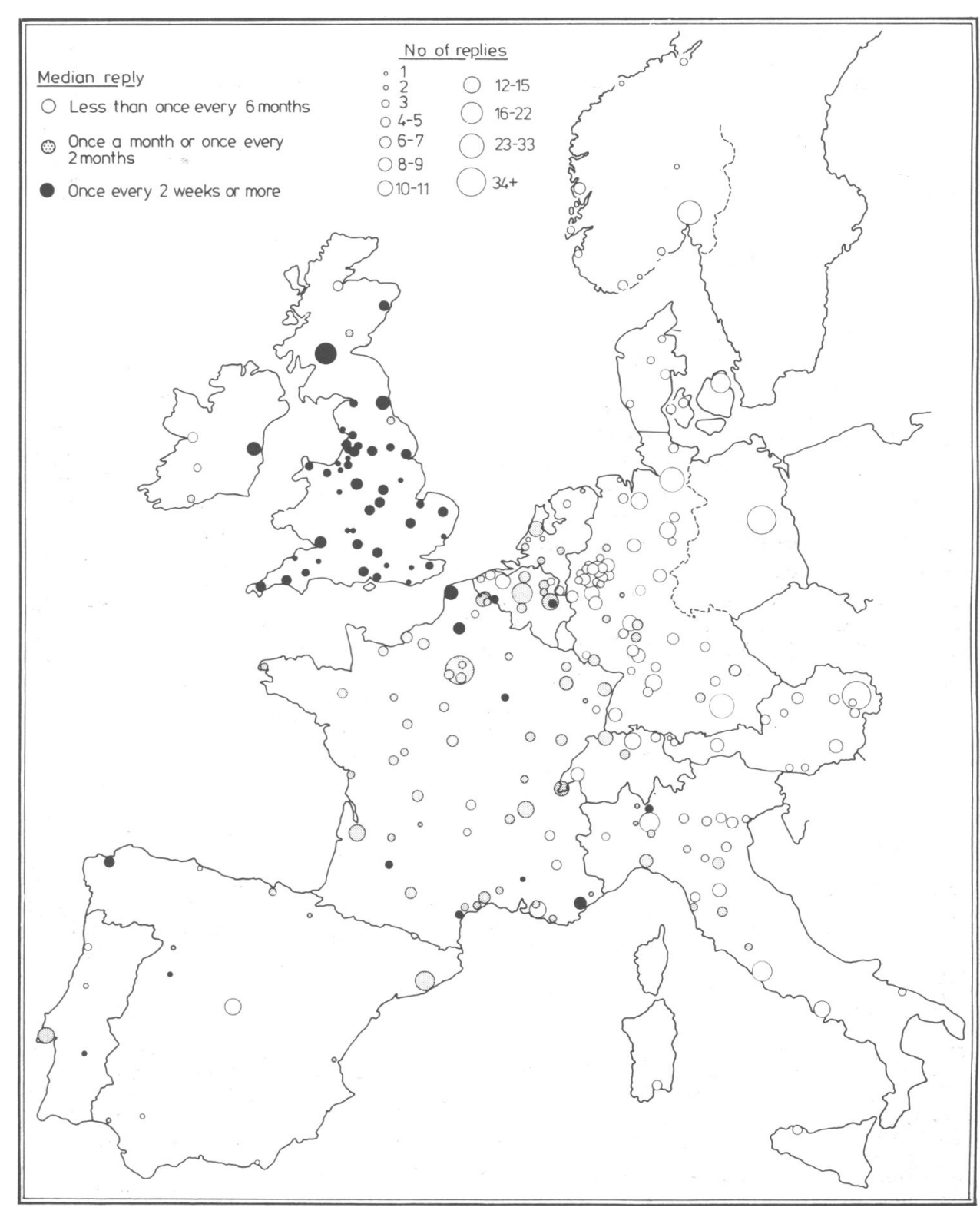

FIG 1-Postal survey of Paget's disease in Europe, based on 1416 radiologists' impressions of how often they 
Fig 1 shows the results. It is based on a total of 1416 replies, since those from specialist radiologists who spent less than half their time in general work were excluded. In fig 1 the area of the circle representing a town is proportional to the number of replies received. The shading indicates the median of the frequencies with which the radiologists reported seeing the disease. To reduce the seven-point scale of frequency to three points and thereby enable display of the results on a black and white map adjacent points were combined. The 50 replies received from Norway during the pilot study are included on the map because the median frequency for every town was once a year or less. These results could therefore be directly compared with those of the main survey, as expressed on the three-point scale.

The map shows clear trends. The disease was most common in Britain. In France the frequency was less and from there the frequencies declined to the south, east, and north-east.

\section{RADIOLOGICAL SURVEY}

The table and fig 2 show the results of the radiological survey. The prevalence rates for each sex were directly standardised to allow comparisons corrected for the differing age distributions of the subjects in the various towns. The standardisation procedure used five-year age distributions from 55 to 90 and over. As in previous surveys, ${ }^{3}$ the combined population of the 14 British towns initially studied was used as the standard so that the results of all surveys are directly comparable. In the table the towns are listed in descending order of

Prevalence of Paget's disease among hospital patients aged 55 years and over in 13 towns

\begin{tabular}{|c|c|c|c|c|c|c|}
\hline \multirow{2}{*}{ Country } & \multirow{2}{*}{ Town } & \multirow{2}{*}{$\begin{array}{c}\text { No of } \\
\text { patients }\end{array}$} & \multirow{2}{*}{$\begin{array}{c}\text { No with } \\
\text { disease }\end{array}$} & \multicolumn{3}{|c|}{ Prevalence $\left({ }^{\circ}\right)$ of Paget's disease } \\
\hline & & & & $\begin{array}{c}\text { Men* } \\
(n=6505)\end{array}$ & $\begin{array}{l}\text { Women* } \\
(\mathrm{n}=5313)\end{array}$ & $\begin{array}{c}\text { Both } \\
\text { sexes } \dagger\end{array}$ \\
\hline France & Bordeaux & 946 & 35 & 3.9 & 1.5 & $2 \cdot 7$ \\
\hline France & Rennes & 934 & 34 & $3 \cdot 7$ & 1.0 & $2 \cdot 4$ \\
\hline France & Nancy. & 939 & 14 & $2 \cdot 7$ & $1 \cdot 2$ & $2 \cdot 0$ \\
\hline Spain & Valencia & 749 & 8 & $0 \cdot 7$ & 1.9 & $1 \cdot 3$ \\
\hline Germany & Essen & 972 & 10 & $1 \cdot 4$ & $1 \cdot 2$ & 1.3 \\
\hline Denmark & Copenhagen & 1006 & 12 & 1.4 & 0.8 & $1 \cdot 1$ \\
\hline Italy & Milan & 1061 & 11 & 1.6 & $0 \cdot 4$ & 1.0 \\
\hline Spain & La Coruna & 1017 & 11 & 1.0 & 0.9 & 0.9 \\
\hline Austria & Innsbruck & 1041 & 6 & 0.7 & 0.6 & 0.7 \\
\hline Holland & Drachten & 716 & 5 & $1 \cdot 3$ & $0 \cdot 0$ & 0.6 \\
\hline Greece & Athens & 901 & 4 & 0.6 & 0.3 & 0.5 \\
\hline Italy & Palermo & 509 & 2 & $0 \cdot 3$ & $0 \cdot 7$ & 0.5 \\
\hline Sweden & Malmo & 1027 & 5 & $0 \cdot 2$ & 0.6 & $0 \cdot 4$ \\
\hline
\end{tabular}

*Age standardised rates. †Age- and sex-standardised rates.

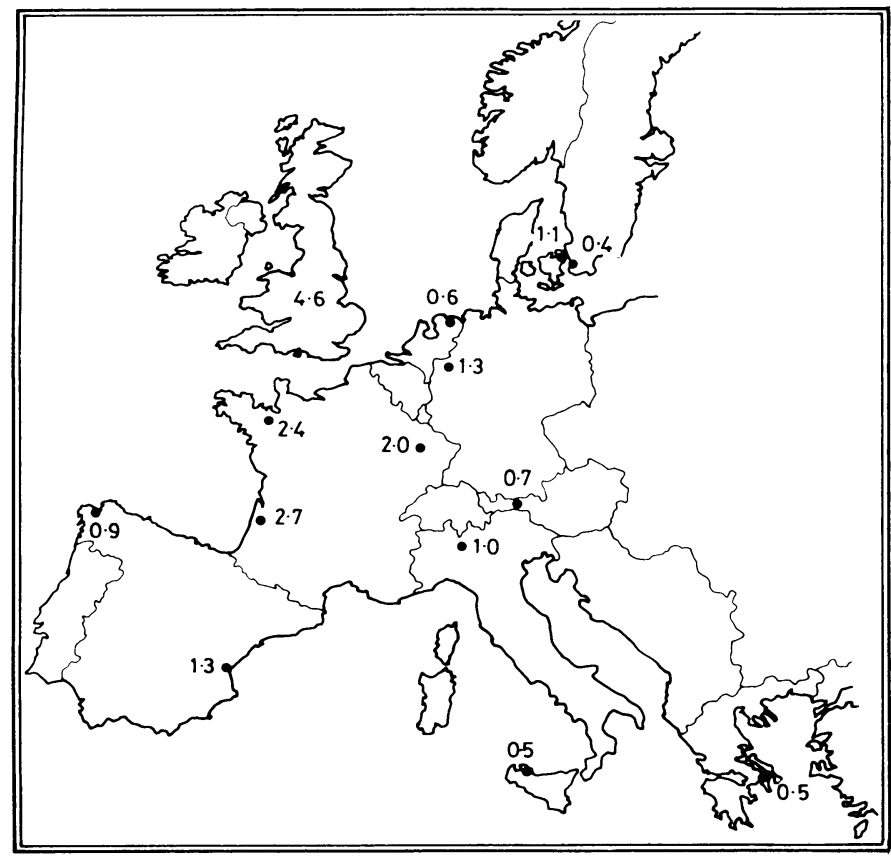

FIG 2-Age- and sex-standardised prevalences (\%) of Paget's disease among hospital patients aged 55 years and over in 13 European towns, and in Britain (see text). the overall age- and sex-standardised prevalences (final column) which ranged from $2.7 \%$ in Bordeaux to $0.4 \%$ in Malmo (Sweden)

The results corroborate those of the postal questionnaire. The highest prevalences were in the three French towns, Bordeaux $(2 \cdot 7 \%)$ Rennes $(2.4 \%)$, and Nancy $(2.0 \%)$. These prevalences were lower than the overall prevalence of $4.6 \%$ among non-skeletal radiographs in Britain. In the remaining towns the prevalences ranged from $1.3 \%$ in Valencia (Spain) and Essen (West Germany), to $0.5 \%$ in Palermo (Sicily) and Athens and $0.4 \%$ in Malmo

As would be expected, the prevalences among men were higher than those among women, except in three towns where the numbers of cases were small. The prevalences in the three French towns were comparable with the lowest values recorded in Britain $(2.7 \%$ in Carlisle and $2.3 \%$ in Aberdeen in radiographs which included about $20 \%$ of skeletal films).

The extent of between- and within-observer variation in the interpretation of the radiographs was assessed. In each town the radiologist examined a $10 \%$ sample of films initially classified as negative. For only one radiograph out of about 1150 was reclassification necessary. In the town where this occurred the radiologist examined an additional $10 \%$ sample of negative films to ensure that no systematic bias, perhaps due to quality of radiographs, had occurred. No further reclassifications were necessary.

At the end of the survey the radiologist re-examined a sample of 42 radiographs from four towns. Of this sample $31(74 \%)$ had been initially classified as definite or doubtful cases, a proportion far greater than that of $2.4 \%$ in the main survey. The radiologist's re-examination was carried out in such a way that he was unaware of his earlier report on the films. The agreement between the first and second examinations was $90 \%$, with only four radiographs reclassified. When the results of this observer variability study were put in the context of the mix of radiographs in the main survey they indicated an overall withinobserver agreement level of more than $99 \%$.

\section{Discussion}

This survey of the radiological prevalence of Paget's disease has shown sharp geographical variations within Europe. The postal questionnaire sent to a sample of radiologists showed an overall pattern which was corroborated by radiological surveys in the 13 towns.

The postal questionnaire is a crude technique. The frequency with which a radiologist sees radiographs with signs of Paget's disease will be influenced by factors other than the prevalence of the disease, such as his or her work load. There was a sharp disparity between the results of the postal questionnaire and those of the radiological survey in only one centre. The high frequency with which the radiologists saw the disease in this town, where the prevalence was subsequently found to be low, seemed to be mainly the result of the large number of radiographs reported on daily.

The frequency with which the disease is seen would also depend on the nature of the radiologist's work. If he is exclusively a general radiologist he is likely to see it more often than if he also does sessions as a specialist in, say, chest radiography, in which evidence of the disease is rarely seen, or paediatric radiography, where the age group is inappropriate.

Our impression during the radiological survey was that variations in diagnostic criteria from one country to another did not influence responses to the postal questionnaire. While severe disease was generally recognised, however, usually as part of the differential diagnosis of secondary bone tumours, early disease tended to be overlooked.

Despite the fallibility of the postal questionnaire and the relatively low response rate there was a remarkable concordance with the results of the radiological survey. From town to town within any one country the medians of the radiologists' replies were surprisingly consistent. The range of prevalence in Europe, however, as indicated by their replies, exaggerated that demonstrated by the radiological survey. This exaggeration is probably a product of influences already mentioned-namely, variations in work load and nature of work.

The prevalence of the disease among patients attending for routine radiological investigations must be a biased estimate of 
the true prevalence of the disease in the community. In the radiological survey, in an attempt to achieve greater comparability between the populations surveyed in each town, radiographs in private hospitals were not used. Also radiographs taken specifically to show the skeleton were exluded. Therefore the differences in prevalences cannot be attributed to differing levels of clinical suspicion of Paget's disease among doctors referring patients for skeletal radiographs or to differing access to radiology among patients with skeletal symptoms. The large differences in prevalence shown by the radiological survey are unlikely to have been greatly affected by the biases of the method.

Our conclusion is that Paget's disease is more prevalent in Britain than in any other Western European country. Only in France do prevalences reach those in Britain. In the survey of 31 British towns the age- and sex-standardised prevalences ranged from 8.3 to $2 \cdot 3 \%$. (This survey included skeletal radiographs, which increased the overall British prevalence by $0.4 \%$ -that is, from $4.6 \%$ to $5.0 \%$.) The prevalences recorded in the three French towns were therefore similar to the lowest prevalences recorded in Britain. In the remaining countries the prevalences were much lower, ranging from $1.3 \%$ in Valencia (Spain) and Essen (West Germany) to $0.5 \%$ in Palermo (Sicily) and Athens, and $0.4 \%$ in Malmo (Sweden). Corroboration of the very low rates in Sweden comes from a previous survey using the same technique, where the prevalence was $0.3 \% .^{2}$ Radiological and clinical data from Norway ${ }^{4}$ and Finland clearly indicate the rarity of the disease. ${ }^{2}$

The prevalence ${ }^{5}$ in Europe may be compared with those in America and Australia. Studies using the same technique and radiologist found an age- and sex-standardised prevalence among white Americans of $3.9 \%$ in New York and $0.9 \%$ in Atlanta. In Perth (Australia) the prevalence among native-born Australians was $3 \cdot 2 \%$.

The description of geographical variations in the prevalence of Paget's disease in Europe is important both because it has to be reconciled with existing hypotheses about the causation of the disease and also because it may be used to generate new hypotheses.

Recently osteoclast cells in Pagetoid bone have been shown to contain inclusion bodies, whose similarity to paramyxovirus nucleocapsides raises the possibility that the disease is due to a viral infection. ${ }^{6}$ On the one hand, however, the virus must be capable of considerable penetration within populations, for the disease affects up to $8.3 \%$ of people aged 55 and over in British towns. On the other hand, its penetration, in so far as this is indicated by the prevalence of the disease, is poor in adjacent populations-notably, Scandinavia and in densely populated areas, such as Essen. There is no parallel with any other human viral illness and it seems necessary to postulate the existence of one or more as yet unknown cofactors. Vitamin D deficiency has previously been suggested as a possible factor. ${ }^{7}$

In an attempt to identify causal factors the geographical findings described here are being followed up by case-control studies in areas of high and low prevalence and comparisons of neighbouring communities with sharply different prevalences.

We are most grateful to the radiologists, other medical staff, and records staff in the towns surveyed. Their kindness and help made the survey possible. The study was funded by grants from Action Research, the Rehabilitation and Medical Research Trust, and Brocades Ltd.

\section{References}

1 Barry HC. Paget's disease of bone. Edinburgh: Churchill Livingstone, 1969. Barker DJP. The epidemiology of Paget's disease. Metab Bone Dis Relat Res $1981 ; 4 / 5: 231-4$.

${ }^{3}$ Barker DJP, Chamberlain AT, Guyer PB, Gardner MJ. Paget's disease of bone: the Lancashire focus. Br Med f 1980;280:1105-7.

4 Falch JA. Paget's disease in Norway. Lancet 1979;ii:1022.

5 Barker DJP, Chamberlain AT, Detheridge FM, Gardner MJ, Guyer PB. Low lead levels in Pagetoid bone. Metab Bone Dis Relat Res (in press).

6 Rebel A, Baslé M, Pouplard A, Kouyoumdjian S, Filmon R, Lepatezour A. Viral antigens in osteoclasts from Paget's disease of bone. Lancet $1980 ;$ ii :344-6.

Barker DJP, Gardner MJ. Distribution of Paget's disease in England, Wales and Scotland and a possible relationship with vitamin D deficiency in childhood. Br f Prev Soc Med 1974;28:226-32.

(Accepted 11 August 1982)
ERINGO, OR SEA-HOLLY. The first leaves of our ordinary Sea-holly, are nothing so hard and prickly as when they grow old, being almost round, and deeply dented about the edges, hard and sharp pointed, and a little crumpled, of a bluish green colour, every one upon a long foot stalk; but those that grow up higher with the stalk, do as it were compass it about. The stalk itself is round and strong, yet somewhat crested, with joints and leaves set thereat, but more divided, sharp and prickly; and branches rising from thence, which have likewise other small branches, each of them having several bluish round prickly heads, with many small jagged prickly leaves under them, standing like a star, and sometimes found greenish or whitish: The root grows wonderfully long, even to eight or ten feet in length, set with rings and circles towards the upper part, cut smooth and without joints down lower, brownish on the outside, and very white within, with a pith in the middle; of a pleasant taste, but much more, being artificially preserved, and candied with sugar.

It is found about the sea coast in almost every county of this land which borders upon the sea. It flowers in the end of Summer, and gives ripe seed within a month after.

The plant is venereal, and breeds seed exceedingly, and strengthens the spirit procreative; it is hot and moist, and under the celestial Balance. The decoction of the root hereof in wine, is very effectual to open obstructions of the spleen and liver, and helps yellow jaundice, dropsy, pains of the loins, and wind cholic, provokes urine, and expels the stone, procures women's courses. The continued use of the decoction for fifteen days, taken fasting, and next to bedward, doth help the stranguary, the difficulty and stoppage of urine, and the stone, as well as all defects of the reins and kidneys; and if the said drink be continued longer, it is said that it cures the stone; it is found good against the French pox. The roots bruised and applied outwardly, help the kernels of the throat, commonly called the king's evil; or taking inwardly, and applied to the place stung or bitten by any serpent, heal it speedily. If the roots be bruised, and boiled in old hog's grease, or salted lard, and broken bones, thorns \&c, remaining in the flesh, they do not only draw them forth, but heal up the place again, gathering new flesh where it was consumed. The juice of the leaves dropped into the ear, helps imposthumes therein. The distilled water of the whole herb, when the leaves and stalks are young, is profitable drank for all the purposes aforesaid; and helps the melancholy of the heart, and is available in quartan and quotidian agues; as also for them that have their necks drawn awry, and cannot turn them without turning their whole body. (Nicholas Culpeper (1616-54) The Complete Herbal, 1850.)

All PLUMS are under Venus, and are like women, some better, and some worse. As there is great diversity of kinds, so there is in the operation of Plums, for some that are sweet moisten the stomach, and make the belly soluble; those that are sour quench thirst more, and bind the belly; the most and waterish do sooner corrupt in the stomach, but the firm do nourish more, and offend less. The dried fruit sold by the grocers under the names of Damask Prunes, do somewhat loosen the belly, and being stewed, are often used, both in health and sickness, to relish the mouth and stomach, to procure appetite, and a little to open the body, allay choler, and cool the stomach. Plum-tree leaves boiled in wine, are good to wash and gargle the mouth and throat, to dry the flux of rheum coming to the palate, gums, or almonds of the ear. The gum of the tree is good to break the stone. The gum or leaves boiled in vinegar, and applied, kills tetters and ringworms. Matthiolus saith, The oil preserved out of the kernels of the stones, as oil of almonds is made, is good against the inflamed piles, the tumours or swellings of ulcers, hoarseness of the voice, roughness of the tongue and throat, and likewise the pains in the ears. And that five ounces of the said oil taken with one ounce of muskadel, drives forth the stone, and helps the cholic. (Nicholas Culpeper (1616-54) The Complete Herbal, 1850.) 